\title{
KEBIJAKAN OUT-REACH DALAM PENANGANAN MIGRAN DI KOTA MAKASSAR
}

\author{
Umiyati Haris $^{1}$, Suryadi Lambali ${ }^{2}$, Sukri $^{3}$, Achmad Zulfikar ${ }^{4}$ \\ Magister Ilmu Politik Universitas Hasannudin ${ }^{1}$, Departemen Ilmu Administrasi Universitas \\ Hasanuddin $^{2}$, Prodi Ilmu Politik Universitas Hasanuddin ${ }^{3}$, Prodi Ilmu Hubungan \\ Internasional Universitas Fajar ${ }^{4}$ \\ Umiyatih12@gmail.com, sukripolitik@gmail.com, apa@kabarfikar.com
}

\begin{abstract}
ABSTRAK
Permasalahan implementasi kebijakan dalam menangani pengungsi di Kota Makassar tidak berjalan secara maksimal meskipun 3 dari 5 program kebijakan Out-Reach berhasil diimplementasikan. Faktor kepentingan aktor pemkot mempengaruhi keberhasilan implementasi kebijakan.Penelitian ini bertujuan untuk menganalisis cara yang digunakan oleh pemerintah Kota Makassar dalam menerapkan kebijakan Out-Reach dan faktor yang mempengaruhi pelaksanaan kebijakan dalam menangani pengungsi di Kota Makassar. Data dikumpulkan melalui teknik wawancara langsung dari staf instansi pemerintah kota, pengungsi di Kota Makassar, dan masyarakat lokal. Metode penelitian menggunakan metode kualitatif dengan jenis studi kasus. Adapun teori yang digunakan adalah neo-institusional dengan konsep aktor dan kepentingan, kebijakan dan implementasi kebijakan.Hasil penelitian menunjukkan bahwa aktor walikota Makassar membentuk pelaksana kebijakan Out-Reach yang hanya melibatkan beberapa instansi pemerintah, seperti Dinas Sosial; Dinas Pendidikan; Dinas Kesehatan; Camat hingga Lurah. Jalur koordinasi dalam mengimplementasikan kebijakan Out-Reach juga menunjukkan ada lembaga non-institusi pemerintah yang berperan sebagai mitra kerja Dinas Sosial, dan komunitas masyarakat yang dilibatkan dalam melaksanakan program-program kebijakan Out-Reach dalam menangani pengungsi di Kota Makassar. Faktor yang mempengaruhi pelaksanaan kebijakan Out-Reach yaitu faktor pendukung dan faktor penghambat. Faktor pendukung yaitu adanya pembentukan citra oleh aktor walikota Makassar untuk menjadi role model dalam menerapkan kebijakan penanganan pengungsi di tingkat daerah; keterlibatan aktor noninstitusi pemerintah. Adapun faktor penghambat yaitu: jalur koordinasi tidak terstruktur; dan sosialisasi tidak menyeluruh. Disimpulkan bahwa pelaksanaan kebijakan Out-Reach melibatkan aktor non-institusi pemerintah selain dari internal institusi yang telah dibentuk oleh aktor walikota Makassar, serta dalam pelaksanaan kebijakan hanya tiga dari lima program yang berhasil diimplementasikan. Diharapkan jalur koordinasi dan komunikasi yang terstruktur dari walikota hingga ke tingkat lurah dalam mencapai keberhasilan implementasi kebijakan.
\end{abstract}

Kata Kunci : Kebijakan Out-Reach, aktor institusi pemerintah, aktor non-institusi pemerintah, role model, implementasi kebijakan

\section{ABSTRACT}

The problem of policy implementation in handling refugee in Makassar City has been not running optimally, even though 3 out of 5 Out-Reach policy program are being successfully 
implemented. The interest factor affected policy successful implementation. This study was intended to analyze the method used by The Government of Makassar in applying Out-Reach Policy and factor which influence the implementation of policy in handling refugee in Makassar City. Data collected through interview technique from the city government institution staff, the refugee in Makassar City, and the local community. The research method use a qualitative method with a case study. As for theory that use is the neo-institutional theory with some of the concepts: actor and its interest, policy, and policy implementation.The research result shows that actor of the mayor of Makassar has established the Out-Reach Policy executor which only involves several government agencies, such as Social Services; Education Authorities; Public Health Office; Sub-district to the urban village. The coordination line in implementing Out-Reach Policy also shows there is involvement of non-government institution actors. Based on the coordination line discovered that non-government institution has a role as work partners of Social Services and the local community that involved in implementing policies programs of Out-Reach in handling refugee in Makassar City. Factors that affect the implementation of Out-Reach Policy are supporting factors and obstacle factors. The supporting factors are: image formation by the actor of the mayor of Makassar to become a role model in implementing refugee handling policy at the regional level; and the involvement of non-institutional government actors. As for the obstacle, factors are: unstructured coordination path and socialization is not comprehensive. Concluded that the implementing of Out-Reach Policy involve non-government institution actors other than from the internal institution which has been formed by the actor of the mayor of Makassar and in the implementation of the policy only three from five programs that successfully implemented. A structured coordination and communication line is expected from the mayor to the urban village level to achieve policy successfully implemented.

Keywords : Out-Reach Policy, government institution actor, non-government institution actor, role model, policy implementation

\section{PENDAHULUAN}

Kota Makassar sebagai salah satu kota di Indonesia yang menjadi tempat tujuan pengungsi dan pencari suaka memerlukan kebijakan yang mengatur penanganannya. Pemerintah Kota Makassar, dalam hal ini Walikota Makassar, melakukan penandatanganan Nota Kesepahaman atau MoU dengan IOM terkait penanganan pengungsi yang ada di kota Makassar pada tanggal 21 September 2015. Tujuannya adalah agar penanganan pengungsi tidak keluar dari wewenang Walikota serta terarah dan dapat ditangani oleh seluruh instansi hingga masyarakat kota Makassar. Sehingga dihasilkan kebijakan dari beberapa program yang disebut Out-REACH.

Kebijakan Out-REACH dilihat melalui pendekatan neo-institusional atau institusionalisme baru. Institusionalisme Baru dipicu oleh pendekatan behavioralis yang melihat politik dan kebijakan publik sebagai hasil dari perilaku kelompok besar atau massa, dan pemerintah sebagai institusi yang hanya mencerminkan kegiatan massa (Miriam, 2008). Pemerintah Kota Makassar dalam hal ini adalah walikota Makassar merupakan aktor yang 
membentuk struktur lembaga untuk melaksanakan kebijakan Out-REACH. Aktor walikota dilihat sebagai individu yang tidak dibatasi oleh baik lembaga formal maupun informal, tapi akan membuat pilihan mereka sendiri (Fajar S. dan Tri H. W., 2016). Jadi, dalam penelitian ini akan membuktikan dan menganalisis keterlibatan lembaga informal atau aktor noninstitusi pemerintah dalam mempengaruhi keberhasilan implementasi kebijakan OutREACH.

Kebijakan Out-REACH penting untuk diteliti keberhasilan implementasinya dalam menangani pengungsi di Kota Makassar. hal tersebut disebabkan karena kebijakan Out$R E A C H$ terdiri dari beberapa program yang merupakan inisiatif pemerintah Kota Makassar yang belum pernah dibuat oleh pemerintah daerah/kota lainnya di Indonesia. Selain itu, permasalahan pengungsi di Indonesia memerlukan kebijakan sebagai bentuk perlindungan hukum di wilayah Indonesia.Hal tersebut sesuai dengan penelitian sebelumnya yang menguraikan tentang definisi pengungsi, suaka dan pencari suaka, hingga standar internasional perlakuaan terhadap pengungsi berdasarkan hukum internasional berupa Konvensi 1951 tentang Status Pengungsi. Selain itu, penelitian ini menguraikan mengenai pengungsi di Indonesia serta instrumen hukum yang melindungi pengungsi yang akan membentuk kebijakan penanganan pengungsi ataupun pencari suaka di Indonesia (Ajat, 2004). Kebijakan penanganan pengungsi di suatu wilayah juga digambarkan dalam sebuah penelitian yang menjelaskan penanganan pengungsi di Provinsi Nusa Tenggara timur sampai dengan batas waktu 31 Desember 2002 didasarkan pada asumsi, interpretasi, dan "angka kepentingan" yang berbeda dari masing-masing pelaku kebijakan. Dampak dari kebijakan pemukiman kembali bagi pengungsi, yaitu pengungsi ditangani hanya sementara waktu, dan Pemerintah terlihat tidak tegas sehingga pengungsi hidup dengan sangat prihatin, serta kehidupan sosial, ekonomi dan budaya yang rapuh. Sedangkan dampak kebijakan pemukiman kembali terhadap penduduk lokal yaitu berdampak negatif, karena sering terlibat konflik internal dengan masyarakat, pengrusakan tanaman dan lahan (Thobias, 2003).

Beberapa ketidaksesuaian penerapan kebijakan Out-REACH dalam penanganan pengungsi dan pencari suaka di Kota Makassar, yaitu pelaksanaan program tidak merata ke seluruh kecamatan yang ditempati oleh pengungsi dan pencari suaka di Kota Makassar. Ada kecamatan dimana program Out-REACH tidak berjalan maksimal. Seperti pengungsi dan pencari suaka yang menetap di Kecamatan Mariso dibuatkan kegiatan yang merupakan salah satu bentuk dari program Out-REACH, seperti pemberdayaan pengungsi dan pencari suaka dalam hal tata lorong. Akan tetapi, bagi pengungsi dan pencari suaka yang menetap di kecamatan selain Mariso, tidak ada kegiatan seperti itu. Penulis memiliki asumsi bahwa hal 
tersebut dipengaruhi oleh aktor walikota Makassar yang bertempat tinggal di sekitar wilayah Mariso. Peran serta kharismanya membuat efektif dilaksanakannya program pemberdayaan pengungsi dan pencari suaka di wilayah tersebut.

Sehingga, permasalahan tersebut membuat penulis berasumsi bahwa program OutREACH ini kurang maksimal dalam implementasinya di Kota Makassar karena ada kecamatan dimana terdapat shelter atau tempat tinggal pengungsi dan pencari suaka, namun tidak ada sosialisasi maupun kegiatan dari Pemerintah Kota Makassar. Selain itu, permasalahan juga timbul ketika terdapat pengungsi dan pencari suaka yang berkelahi. Padahal salah satu esensi dari program Out-REACH ini adalah menciptakan kenyamanan antar-pengungsi dan pencari suaka dengan masyarakat lokal di Kota Makassar.

Selain itu, asumsi penulis atas pemerintah Kota Makassar yang memiliki kepentingan dalam menerapkan kebijakan Out-REACH untuk melibatkan pengungsi dalam mewujudkan program tata lorong dan Makassar Bersih. Dengan demikian diperlukan kajian mendalam untuk menganalisis kepentingan aktor pemerintah KotaMakassar dalam menangani pengungsi yang diatur melalui sebuah kebijakan. Penelitian ini ingin melihat cara yang digunakan oleh pemerintah Kota Makassar dalam melaksanakan kebijakan Out-REACH dan faktor yang mempengaruhi pelaksanaan kebijakan dalam menangani pengungsi di Kota Makassar.

\section{METODE PENELITIAN}

Penelitian ini dilakukan di wilayah Kota Makassar Sulawesi Selatan. Jenis penelitian yang digunakan adalah studi kasus dengan menggunakan pendekatan kualitatif.

Populasi dan sampel dalam penelitian ini yakni populasi adalah seluruh pengungsi yang berada di Kota Makassar dan pemerintah Kota Makassar. Sampel sebanyak 5 instansi pemerintah kota yang terdiri dari Dinas Sosial; dinas Pendidikan; Dinas Kesehatan Kota Makassar; serta Camat dan Lurah di wilayah Kecamatan Mariso dan Tamalanrea yang dipilih berdasarkan kriteria informan kunci.Informan kunci atau informan yang baik memiliki karakteristik dapat memahami kultur setempat dan menyaksikan kejadian-kejadian penting serta harus terlibat di lapangan pada saat itu (Rulam, 2014). Adapun pemilihan sampel untuk pengungsi menggunakan teknik focusgroup disscussion (FGD)dengan model wawancara kelompok (Agus, 2006) di wilayah Kecamatan Mariso dan Tamalanrea yang berasal dari Afghanistan dan Myanmar.

Teknik pengumpulan data dilakukan melalui penelitian lapangan dengan teknik observasi secara langsung untuk mengetahui keberadaan rumah akomodasi, kegiatan dan 
pertambahan jumlah pengungsi di Kota Makassar. Selain itu, teknik wawancara secara langsung juga digunakan untuk mengetahui jalur koordinasi kebijakan Out-REACH, perilaku aktor dalam mengimplementasikan kebijakan serta kepentingan aktor pemerintah kota melalui kebijakan penanganan pengungsi di Kota Makassar. Wawancara bagi pengungsi menggunakan teknik focus group discussion.

Teknik analisis data dalam penelitian ini diperoleh dari hasil wawancara yang kemudian diubah menjadi bentuk transkrip wawancara. Bentuk transkrip tertulis itu kemudian dipilih data yang relevan dengan pertanyaan penelitian, setelah itu data diuraikan kedalam bentuk deskripsi kata-kata. Adapun data yang diperoleh melalui proses observasi, penulis mengamati melalui indera penglihatan dan pendengaran terhadap objek penelitian, seperti kondisi rumah akomodasi pengungsi dan pencari suaka serta kegiatan pemberdayaan mereka dalam berbagai kegiatan. Hasil observasi akan menuntun penulis memperoleh data berupa gambar atau informasi lainnya yang telah dilaksanakan pada 2 hingga 3 tahun yang lalu.

Hasil observasi akan didokumentasikan melalui bentuk gambar dan deskripsi berdasarkan apa yang diamati. Seluruh data melalui proses reduksi data, yaitu proses pemilihan dan penyederhanaan sebelum disajikan dalam bentuk deskripsi kumpulan informasi. Setelah itu, dilakukan verifikasi dan penarikan kesimpulan. Sedangkan data yang penulis peroleh melalui studi pustaka akan digunakan sebagai data pendukung untuk melengkapi data primer. Setelah itu, analisis penulis akan tergambar melalui penggabungan data primer dan sekunder hingga penarikan kesimpulan.

\section{HASIL DAN PEMBAHASAN}

\section{Pengungsi di Kota Makassar}

Tabel 1 menunjukkan data migran di Kota Makassar yang dirincikan dari bulan Januari hingga Desember tahun 2015. Jumlah migran terbanyak berasal dari negara Afghanistan, jumlahnya pun meningkat hingga Desember 2015 sebanyak 1.123 orang, dimana pada bulan Januari jumlah migran kewarganegaraan Afghanistan hanya 949 orang. Adapun migran yang terbanyak kedua adalah berasal dari Myanmar, sebanyak 243 orang pada bulan Januari dan berkurang di bulan Desember menjadi 226 orang. Adapun jumlah migran yang paling sedikit berasal dari negara Suriah, Mesir dan Yordania.

Jumlah pengungsi di Kota Makassar pada tahun 2017 mengalami pengurangan dibandingkan pada tahun 2015. Seperti yang ditunjukkan pada Tabel 2, dimana total pengungsi di Kota Makassar tahun 2017 adalah 1.855 orang. Adapun jumlah pengungsi 
terbanyak berasal dari Afghanistan dengan total 1.178 orang. Jumlah pengungsi terbanyak kedua masih dari Myanmar dengan total 217 orang. Sedangkan jumlah pengungsi yang tersedikit berasal dari Mesir dan Eritrea, masing-masing 1 orang.Adapun data jumlah pengungsi di Kota Makassar pada tahun 2018 yang diperoleh dari Dinas Sosial Kota Makassar berjumlah 1.859 orang.

\section{Kebijakan Program Out-REACH}

Kerangka kerja umum penanganan pengungsi dan pencari suaka di Kota Makassar menjabarkan kebijakan yang berbentuk program yang disebut sebagai Outreach. Dalam blueprint uraian dari MoU antara Walikota Makassar dan International Organization for Migration (IOM) dalam Penanganan Pengungsi dan Pencari Suaka No. 180.474.32/26/BKS/IX/2015 (Walikota) dan IDN/LCOO/ME0252/2015 (IOM) pada tanggal 21 September 2015 (Kerangka Kerja Umum Penanganan Pengungsi, 2016).

Istilah atau nama $O u t-R E A C H$ terdiri dari beberapa kata sebagai simbol semangat dari program yang akan diuraikan sebagai berikut:

1. R - Respect (Hormat), melalui program ini diharapkan agar pengungsi dan pencari suaka dapat membangun rasa hormat di antara mereka dan hormat kepada masyarakat setempat dengan cara membangun interaksi positif diantara sesama.

2. E-Education (Pendidikan), salah satu komponen kegiatan yang dilaksanakan yaitu mendidik anggota masyarakat dan pemerintah setempat mengenai alasan mengapa pengungsi dan pencari suaka meninggalkan negara mereka dan terdampar di Indonesia. Pengungsi dan pencari suaka juga harus diberi pendidikan bahwa mereka adalah bagian dari masyarakat setempat dan oleh karenanya harus berkontribusi dalam kehidupan masyarakat tempat tinggal mereka.

3. A - Awareness (Kesadaran), masyarakat setempat menyadari keberadaan pengungsi dan pencari suaka di wilayah tempat tinggal mereka dan juga tahu bahwa pengungsi dan pencari suaka hidup dengan rukun dan tahu mengenai pertambahan jumlah pengungsi dan pencari suaka yang tinggal di sekitar mereka.

4. C - Community Service (Layanan Masyarakat), pengungsi dan pencari suaka yang tinggal di tempat akomodasi sementara, di community housing, dan di Rudenim bersama-sama dengan anggota masyarakat setempat dapat melakukan kegiatan pemberian layanan kepada masyarakat secara sukarela yang dapat memberikan manfaat bagi masyarakat keseluruhan. 
5. $\mathrm{H}$ - Hospitality (Keramahan), masyarakat dan pencari suaka/pengungsi dapat bersikap ramah satu sama lain selama pengungsi dan pencari suaka tinggal di lingkungan sekitar.

\section{Koordinasi Pemerintah Kota Makassar dengan Stakeholder dalam Menangani Pengungsi}

Gambar 1 memperlihatkan koordinasi antara walikota Makassar dengan IOM adalah bersifat koordinasi laporan. Begitu pula halnya dengan IOM dan Imigrasi, Polda, UNHCR dan Otoritas Bandara dan Pelabuhan. Pada bagian jalur koordinasi pemerintah Kota Makassar, aktor Walikota yang kemudian diturunkan melalui Ad Hoc, Dknas, Dinsos, BPPA, Dinkes, hingga ke tingkat Camat dan Lurah, menunjukkan pemangku kepentingan yang menjalankan kebijakan blue print penanganan pengungsi dan pencari suaka di Kota Makassar yang ditunjukkan pada bagian atas diagram. Adapun garis hitam putus-putus menunjukkan kegiatan yang dilaksanakan oleh pemangku kepentingan. Adapun koordinasi dari pemkot ke Imigrasi adalah bersifat kegiatan pengawasan yang dilaporkan oleh pihak Lurah.

\section{Peran Pemerintah Daerah dalam Penanganan Migran di Kota Makassar}

Dalam penelitian ini terlihat bahwa keputusan politik aktor pemerintah Kota Makassar sebagai salah satu pembuat kebijakan Out-REACH memiliki cara untuk mengimplementasikan program-program penanganan pengungsi melalui institusi-institusi pemerintah Kota. Sesuai dengan definisi kebijakan yang merupakan serangkaian kegiatan yang mempunyai maksud atau tujuan tertentu yang diikuti dan dilaksanakan oleh seorang aktor atau sekelompok aktor yang berhubungan dengan suatu permasalahan atau hal yang diperhatikan (Agustino, 2008). Dalam hal ini, lembaga-lembaga pemerintah dalam hal ini organisasi perangkat daerah dilibatkan hingga ke tingkat kelurahan. Lembaga-lembaga pemerintah sebagai pelaksana atau implementor program Out-REACH ini direkayasa dan berinteraksi satu dan lainnya untuk mencapai tujuan kebijakan (Peters, 2011). Lembagalembaga yang direkayasa dan berinteraksi satu dan lainnya, yaitu Dinas Sosial; Dinas Pendidikan; Dinas Kesehatan; Camat; dan Lurah. Sehingga, pola rekayasa yang dibentuk berdasarkan peran pemerintah Kota, dalam hal ini walikota Makassar, menjadikan pembahasan kebijakan Out-REACH dilihat dari pendekatan neo-institutionalism atau institusional baru. 
Institusional baru juga melihat pemerintah kota (walikota Makassar) sebagai aktor dalam menentukan jalur koordinasi di tataran lembaga pemerintah tingkat kota. Sejalan dengan definisi aktor yang erat kaitannya dengan sebuah kebijakan dimana aktor memiliki kepentingan yang hendak dicapai (Budi, 2008). Aktor walikota Makassar membentuk ad hoc sebagai ketua pelaksana kebijakan program Out-REACH.Selain itu, ad hoc merupakan gambaran perilaku aktor atau rekayasa yang dibentuk oleh pemerintah kota yang bertugas untuk menjalankan peran khusus dalam melaksanakan kebijakan dalam menangani pengungsi di Kota Makassar.

Pemberian fasilitas pendidikan bagi pengungsi anak secara umum merupakan peran dari Dinas Pendidikan Kota Makassar.Akan tetapi, dalam hal memberikan dukungan pendidikan bagi pengungsi anak, penulis menemukan hanya Dinas Sosial Kota Makassar yang berperan lebih dominan. Hal tersebut disebabkan oleh jumlah pengungsi anak di Kota Makassar yang bersekolah formal hanya sedikit. Kebanyakan pengungsi anak memilih untuk mengikuti fasilitas pembelajaran informal di beberapa rumah akomodasi. Penyebabnya adalah pengungsi anak terkendala di bahasa dan kecemburuan dari anak lokal, sehingga mereka tidak meneruskan untuk bersekolah di sekolah formal.

Adapun peran Dinas Kesehatan dalam melakukan penanganan pengungsi di Kota Makassar yaitu: memberikan pelayanan kesehatan dasar bagi pengungsi melalui Puskesmas. Informasi yang diperoleh dari Dinas Kesehatan, bahwa Dinkes membawahi seluruh Puskesmas, jadi bagi pengungsi yang memperoleh rujukan dari Puskesmas boleh dilayani di Rumah Sakit.Salah satu informan pengungsi Afghanistan juga mengatakan hal yang sama bahwaketika ada pengungsi yang dibawa ke puskesmas, mereka tetap diberi fasilitas namun dengan tetap membayar biaya administrasi.

Sedangkan cara yang ditempuh oleh pemerintah Kota Makassar untuk mengimplementasikan program Respect, Community Service, dan Hospitality adalah dengan memberi peran kepada Camat dan Lurah. Melalui peran melakukan sosialisasi, komunikasi dan koordinasi mengenai keberadaan pengungsi di wilayah masing-masing serta dapat mengundang pengungsi untuk ikut berpartisipasi dalam kegiatan sosial kemasyarakatan, berbagai kegiatan di tingkat kelurahan Tamalanrea yang melibatkan pengungsi seperti pameran skill pengungsi dalam bidang kuliner dan kesenianpada tahun 2017; kerja bakti yang dilaksanakan rutin hingga saat ini; penataan lorong; dan ikut dalam kegiatan International Multicultural Day yang diselenggarakan oleh Kecamatan Mariso di Anjungan Pantai Losari Makassar di tahun 2016. 


\section{Faktor-faktor yang Mempengaruhi Pelaksanaan Kebijakan Out-REACH}

Keberhasilan implementasi kebijakan Out-REACH terdiri atas faktor pendukung dan faktor penghambat. Faktor pendukung berupa citra yang dibentuk oleh pemerintah kota untuk menjadi role model atau panutan bagi pemerintah daerah lain di Indonesia dalam membuat dan mengimplementasikan kebijakan penanganan pengungsi di tingkat kota. Faktor pendukung keberhasilan implementasi kebijakan juga dipengaruhi oleh keterlibatan aktor non-institusi pemerintah. Dinas Sosial Kota Makassar menjadikan Lembaga Studi Kebijakan Publik (LSKP) sebagai mitra kerjasama dalam memberikan pendidikan dan membina pengungsi anak tanpa wali. Selain itu, Komunitas Makassar Bersih (KOMBES) juga terlibat dalam berbagai kegiatan sosial masyarakat yang melibatkan pengungsi, seperti penataan lorong di Jalan Lamadukelleng Buntu Makassar; Acara Buka Puasa Bersama; dan Refugees Learning Community (RLC) yang menampilkan keahlian pengungsi dalam bidang kuliner khas Afghanistan.

Keberhasilan implementasi kebijakan program Community Servicemelalui kegiatan penataan lorong tidak terlepas dari kepentingan aktor walikota, dimana sesuai dengan definisi bahwa proses pembuatan kebijakan tidak terlepas dari kepentingan aktor yang terlibat dalam formulasi hingga pelaksanaan kebijakan (Budi, 2008).Sehingga, ada kepentingan yang hendak dicapai oleh aktor walikota dalam melaksanakan kebijakan Out$R E A C H$ yaitu untuk melibatkan pengungsi dalam kegiatan kerja bakti dan penataan lorong untuk mewujudkan program Makassar Bersih.

Sedangkan faktor penghambat keberhasilan implementasi kebijakan Out-REACH adalah jalur koordinasi tidak terstruktur. Seperti pada jalur koordinasi pemilik akomodasi dengan lurah tidak ada, sehingga tidak ada informasi yang sampai di kecamatan mengenai jumlah pengungsi yang berada di wilayah kecamatan Mariso. Faktor penghambat lainnya adalah sosialisasi tidak tersampaikan kepada seluruh pengungsi di Kota Makassar. Ada pengungsi yang tidak memperoleh sosialisasi pendidikan bagi pengungsi anak, namun ada juga diantara mereka yang mengetahui ada pendidikan formal yang disediakan oleh pemerintah kota. Sosialisasi tidak terlaksana dengan baik disebabkan kurangnya prosedur administrasi.

Tabel 3 menunjukkan pelaksanaan lima program out-reach melaui kegiatan-kegiatan yang sesuai dengan nama dan tujuan dari masing-masing program. Dari 5 program, hanya 3 program yang berhasil diimplementasikan yang ditunjukkan dengan kata 'efektif'. Keberhasilan implementasi kebijakan Out-reach dalam menangani pengungsi di Kota Makassar dilihat berdasarkan konten dan konteks kebijakan yang telah dicapai (Merilee, 
1980). Dalam hal ini, konten dan konteks kebijakan merujuk pada aktor pemkot dalam mengimplementasikan kebijakan Out-reach. Konten kebijakan yang berisi kepentingan pengungsi untuk mencari perlindungan di Kota Makassar tercapai dalam implementasi kebijakan karena pemerintah Kota Makassar telah mengeluarkan kebijakan kerjasama dengan IOM dengan adanya beberapa fasilitas yang mengikutsertakan pengungsi, yang juga menunjukkan pengungsi diterima dengan baik di Kota Makassar. Namun, indikator konten kebijakan berupa tidak adanya pertentangan dengan masyarakat lokal tidak tercapai dalam implementasi kebijakan Out-reach. Penyebabnya adalah program Education kurang efektif dilaksanakan oleh diknas sebagai sumber daya yang dikerahkan oleh aktor walikota untuk mengimplementasikan kebijakan out-reach.

Sedangkan konteks kebijakan Out-reach melihat kepentingan aktor walikota Makassar untuk menjadi role model atau panutan bagi pemerintah daerah/kota lain di Indonesia dalam menerapkan kebijakan penanganan pengungsi di tingkat daerah/kota. Didukung pula dengan karakteristik lembaga untuk menjadikan Makassar sebagai kota dunia, salah satunya adalah panutan dalam menangani permasalahan pengungsi. Akan tetapi, tingkat kepatuhan dan daya tanggap pelaksana terhadap kebijakan out-reach adalah kurang maksimal. Penyebabnya adalah ada koordinasi yang tidak terstruktur dalam mengetahui perkembangan dan penambahan jumlah pengungsi di tingkat Lurah hingga Camat. Sehingga, program Awareness, yaitu sosialisasi ke masyarakat lokal untuk mengetahui perkembangan dan penambahan jumlah pengungsi di masing-masing wilayah tempat tinggal, kurang efektif tercapai dalam implementasi kebijakan. Selain itu, daya tanggap dalam penanganan pengungsi didominasi yang oleh Dinsos dalam implementasinya dengan menjadikan LSKP sebagai mitra kerjasama. Sehingga aktor institusi non-negara yang terlibat juga ikut mempengaruhi keberhasilan implementasi kebijakan.

\section{KESIMPULAN DAN SARAN}

Kami menyimpulkan bahwa dalam mewujudkan implementasi kebijakan out-reach, cara yang dilakukan oleh pemerintah Kota Makassar yaitu dengan membentuk institusi yang terdiri dari Organisasi Perangkat Daerah (OPD) seperti Dinas Pendidikan; Dinas Kesehatan; Dinas Sosial; Camat dan Lurah. Institusi internal yang telah dibentuk akan berinteraksi dalam melaksanakan kebijakan Out-REACH. Disamping itu, faktor pendukung keberhasilan 
implementasi kebijakan Out-REACH adalah keterlibatan aktor non-institusi pemerintah dan citra aktor pemerintah Kota Makassar untuk menjadi role model atau panutan bagi pemerintah daerah lain di Indonesia dalam hal menerapkan kebijakan penanganan pengungsi di tingkat daerah/kota. Sedangkan faktor penghambat keberhasilan implementasi kebijakan Out-REACH terdiri dari jalur koordinasi tidak terstrukturdan sosialisasi program tidak menyeluruh ke seluruh pengungsi dan masyarakat lokal.Upaya untuk mencapai keberhasilan implementasi kebijakan dari program Hospitality, diperlukan koordinasi dan komunikasi yang terstruktur dari walikota hingga ke tingkat lurah. Sehingga Lurah juga dapat mensosialisasikan kebijakan dengan koordinasi dengan pemilik rumah akomodasi dan RT, hingga pelaporan setiap bulan mengenai keberadaan dan pertambahan jumlah pengungsi ke tingkat Camat. Selain itu, umencapai keberhasilan implementasi kebijakan dari program Education, diperlukan support kebijakan agar kekosongan hukum dan aturan dapat diisi.

\section{DAFTAR PUSTAKA}

Ajat H. S. (2004). Pengungsi dalam Kerangka Kebijakan Keimigrasian Indonesia Kini dan yang Akan Datang. Indonesian Journal of International Law, Vol. 2 No. 1 Oktober.

Agus Salim. (2006). Teori dan Paradigma Penelitian Sosial. Edisi Kedua. Yogyakarta: Tiara Wacana.

Agustino L. (2008). Dasar-dasar Kebijakan Publik. Bandung: Alfabeta.

Andistan, Muhammad Abdul Aziz Putra dan Achmad Zulfikar. (2018) "Indonesian Government Challenges in Ratification of the International Convention on Refugees", The Journal of Islamic Studies and International Relations, 3(1), pp. 31-44. Available at: http://jisiera.insiera.org/index.php/jisiera/article/view/3.

Budi.(2008). Orientasi Aktor dalam Perumusan Kebijakan Publik. Masyarakat, Kebudayaan dan Politik, Th. XXI. No. 2, April-Juni 2008, 115-130.

Fajar S. dan Tri H. W. (2016). Pembiaran Pada Potensi Konflik dan Kontestasi Semu Pemilukada Kota Blitar: Analisis Institusionalisme Pilihan Rasional. Politik Indonesia: Indonesian Political Science Review, 1 (2): 136-153.

Kerangka Kerja Umum Penanganan Pengungsi dan Pencari Suaka di Kota Makassar.

(2016). Diturunkan dari MoU Nota Kesepahaman antara Walikota Makassar dan International Organization fo Migration dalam Penanganan Pengungsi dan Pencari Suaka No. 180.474.32/26/BKS/IX/2015 (Walikota) dan IDN/LCOO/ME0252/2015 (IOM) pada tanggal 21 September 2015.

Merilee G.(1980). Politics and Policy Implementation the Third World.New Jersey: Priceton University Press.

Miriam B. (2008). Dasar-dasar Ilmu Politik. Jakarta: Gramedia. 
Peters B.G. (2011). Institutional Theory in Political Science: The New Institutionalism. USA: Bloomsbury Publishing.

Rulam A. (2014). Metodologi Penelitian Kualitatif. Cet. ke-1. Yogyakarta: Ar-Ruzz Media.

Thobias M. A.(2003). Kebijakan Pemukiman Kembali Pengungsi di Perbatasan IndonesiaTimor Leste (Studi Kasus: Kecamatan Tasifeto Timur, Kabupaten Belu, Provinsi Nusa Tenggara Timur). (Tesis). Semarang: Universitas Diponegoro.

Robyn C. Sampson, Sandra M. Gifford \& Savitri Taylor (2016) The myth of transit: the making of a life by asylum seekers and refugees in Indonesia, Journal of Ethnic and Migration Studies, 42:7, 1135-1152, DOI: 10.1080/1369183X.2015.1130611 


\section{Lampiran}

Tabel 1. Jumlah Pengungsi di Kota Makassar Tahun 2015

KEBANGSAAN

NO BLN

AFG MMR IRN SOM SDN IRQ LKA ETH PAK PSE ERI SYR EGY YEM JOR

\begin{tabular}{cccccccccccccccccc}
\hline 1 & Jan & 949 & 243 & 192 & 213 & 77 & 39 & 34 & 30 & 27 & 12 & 3 & - & - & - & 1 & 1.820 \\
\hline 2 & Feb & 940 & 243 & 181 & 206 & 69 & 39 & 34 & 28 & 25 & 7 & 3 & - & - & - & 1 & 1.776 \\
\hline 3 & Mar & 943 & 241 & 170 & 205 & 73 & 39 & 34 & 31 & 25 & 7 & 3 & - & - & - & 1 & 1.772 \\
\hline 4 & Apr & 945 & 238 & 165 & 201 & 73 & 39 & 34 & 30 & 25 & 5 & 3 & - & - & - & - & 1.758 \\
\hline 5 & Mei & 940 & 234 & 163 & 197 & 75 & 39 & 34 & 32 & 25 & 5 & 3 & - & - & - & - & 1.747 \\
\hline 6 & Juni & 960 & 240 & 163 & 185 & 77 & 44 & 34 & 32 & 30 & 6 & 3 & - & - & - & - & 1.774 \\
\hline 7 & Juli & 1.020 & 241 & 156 & 205 & 82 & 48 & 34 & 32 & 37 & 7 & 2 & 1 & 1 & 2 & - & 1.869 \\
\hline 8 & Agst & 1.035 & 241 & 159 & 204 & 82 & 48 & 34 & 28 & 40 & 13 & 2 & 1 & 1 & 2 & - & 1.890 \\
\hline 9 & Sept & 1.068 & 235 & 155 & 203 & 70 & 48 & 34 & 32 & 43 & 12 & 2 & 1 & 1 & 2 & - & 1.906 \\
\hline 10 & Okt & 1.086 & 233 & 148 & 199 & 71 & 52 & 34 & 32 & 43 & 12 & 2 & 1 & 1 & 2 & - & 1.916 \\
\hline 11 & Nov & 1.064 & 225 & 148 & 175 & 65 & 52 & 34 & 31 & 43 & 12 & 2 & 1 & 1 & 2 & - & 1.855 \\
\hline 12 & Des & 1.123 & 226 & 149 & 168 & 65 & 48 & 34 & 31 & 43 & 12 & 2 & 1 & 1 & 2 & - & 1.906 \\
\hline
\end{tabular}

*PSE: Palestina; ERI: Eritrea; JOR: Yordania; YEM: Yaman; EGY: Mesir; LKA: Sri Lanka; AFG: Afghanistan; MMR: Myanmar; IRN: Iran; SOM: Somalia; SDN: Sudan; IRQ: Iraq 
Tabel 2. Jumlah Pengungsi di Kota Makassar Tahun 2017

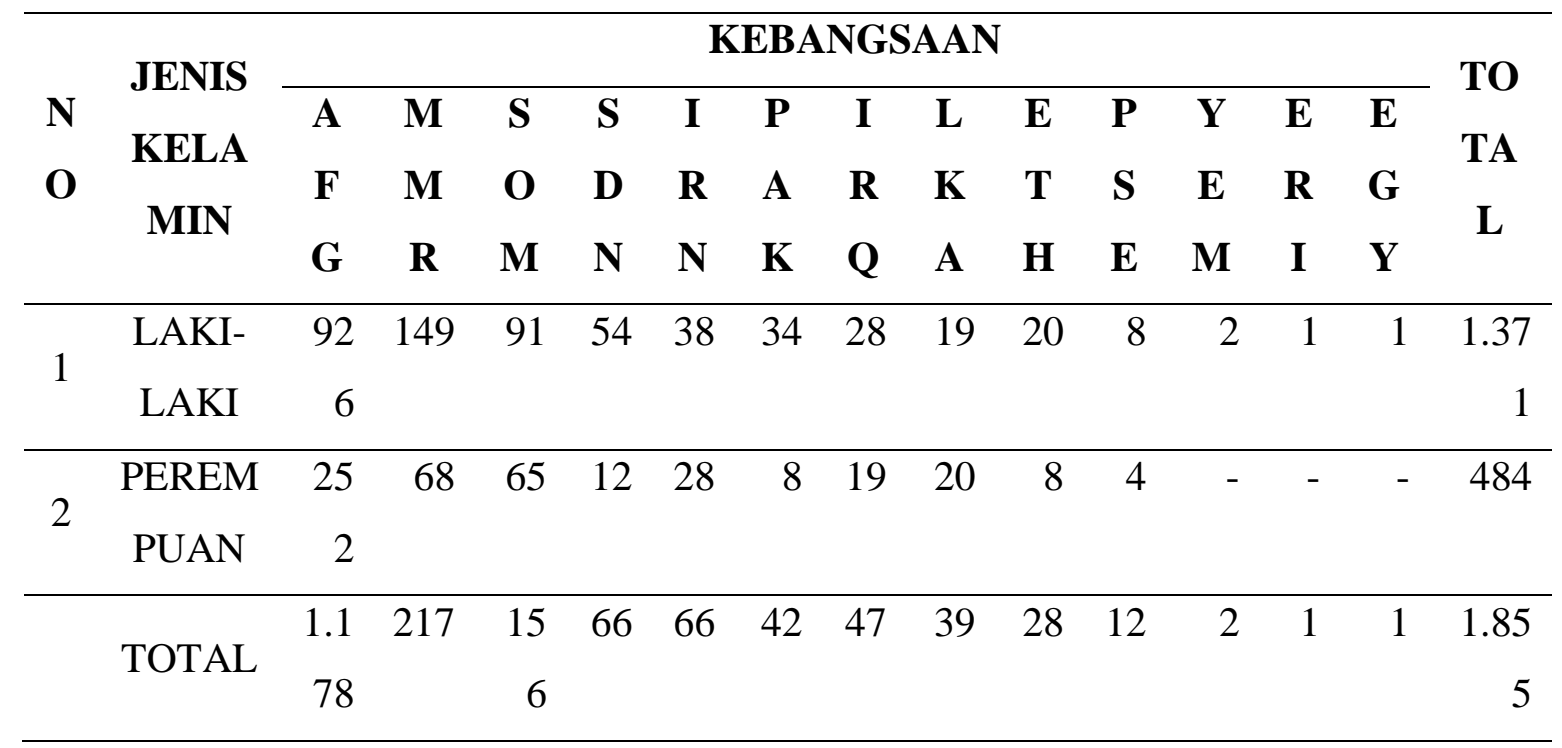

*PSE: Palestina; ERI: Eritrea; JOR: Yordania; YEM: Yaman; EGY: Mesir; LKA: Sri Lanka; AFG: Afghanistan; MMR: Myanmar; IRN: Iran; SOM: Somalia; SDN: Sudan; IRQ: Iraq 
Tabel 3. Keberhasilan Implementasi Kebijakan Out-REACH

\begin{tabular}{|c|c|c|c|c|}
\hline Program & Kegiatan & Koordinasi & Efektivitas & Kendala \\
\hline \multirow{3}{*}{ Respect } & Kerja Bakti & Camat-Lurah & Efektif & - \\
\hline & $\begin{array}{l}\text { Pameran Kerajinan } \\
\text { Pengungsi }\end{array}$ & Camat-Lurah & Efektif & - \\
\hline & $\begin{array}{c}\text { International } \\
\text { Multicultural Day }\end{array}$ & Ad hoc-Camat & Efektif & - \\
\hline Education & $\begin{array}{l}\text { Mengikutsertakan } \\
\text { pengungsi anak } \\
\text { bersekolah di sekolah } \\
\text { formal }\end{array}$ & $\begin{array}{c}\text { Dinas } \\
\text { Pendidikan }\end{array}$ & $\begin{array}{l}\text { Kurang } \\
\text { Efektif }\end{array}$ & $\begin{array}{l}\text { Aturan } \\
\text { Perundang- } \\
\text { undangan }\end{array}$ \\
\hline Awareness & $\begin{array}{c}\text { Kesadaran masyarakat } \\
\text { lokal mengenai } \\
\text { keberadaan dan } \\
\text { pertambahan jumlah } \\
\text { pengungsi di wilayah } \\
\text { mereka } \\
\end{array}$ & Camat-Lurah & $\begin{array}{l}\text { Kurang } \\
\text { Efektif }\end{array}$ & $\begin{array}{l}\text { Jalur koordinasi } \\
\text { tidak terstruktur }\end{array}$ \\
\hline \multirow{3}{*}{$\begin{array}{l}\text { Community } \\
\text { Service }\end{array}$} & Kerja Bakti & Camat-Lurah & Efektif & - \\
\hline & $\begin{array}{l}\text { Pameran Kerajinan } \\
\text { Pengungsi }\end{array}$ & Camat-Lurah & Efektif & - \\
\hline & $\begin{array}{c}\text { Pelayanan Kesehatan } \\
\text { bagi Pengungsi di } \\
\text { Puskesmas }\end{array}$ & $\begin{array}{c}\text { Dinas } \\
\text { Kesehatan }\end{array}$ & Efektif & - \\
\hline \multirow{4}{*}{ Hospitality } & Kerja Bakti & Camat-Lurah & Efektif & - \\
\hline & $\begin{array}{l}\text { Pameran Kerajinan } \\
\text { Pengungsi }\end{array}$ & Camat-Lurah & Efektif & - \\
\hline & $\begin{array}{c}\text { International } \\
\text { Multicultural Day }\end{array}$ & Ad hoc-Camat & Efektif & - \\
\hline & $\begin{array}{c}\text { Pelayanan Kesehatan } \\
\text { bagi Pengungsi di } \\
\text { Puskesmas }\end{array}$ & $\begin{array}{c}\text { Dinas } \\
\text { Kesehatan }\end{array}$ & Efektif & - \\
\hline
\end{tabular}

*Kata 'efektif' menunjukkan keberhasilan implementasi kebijakan. 


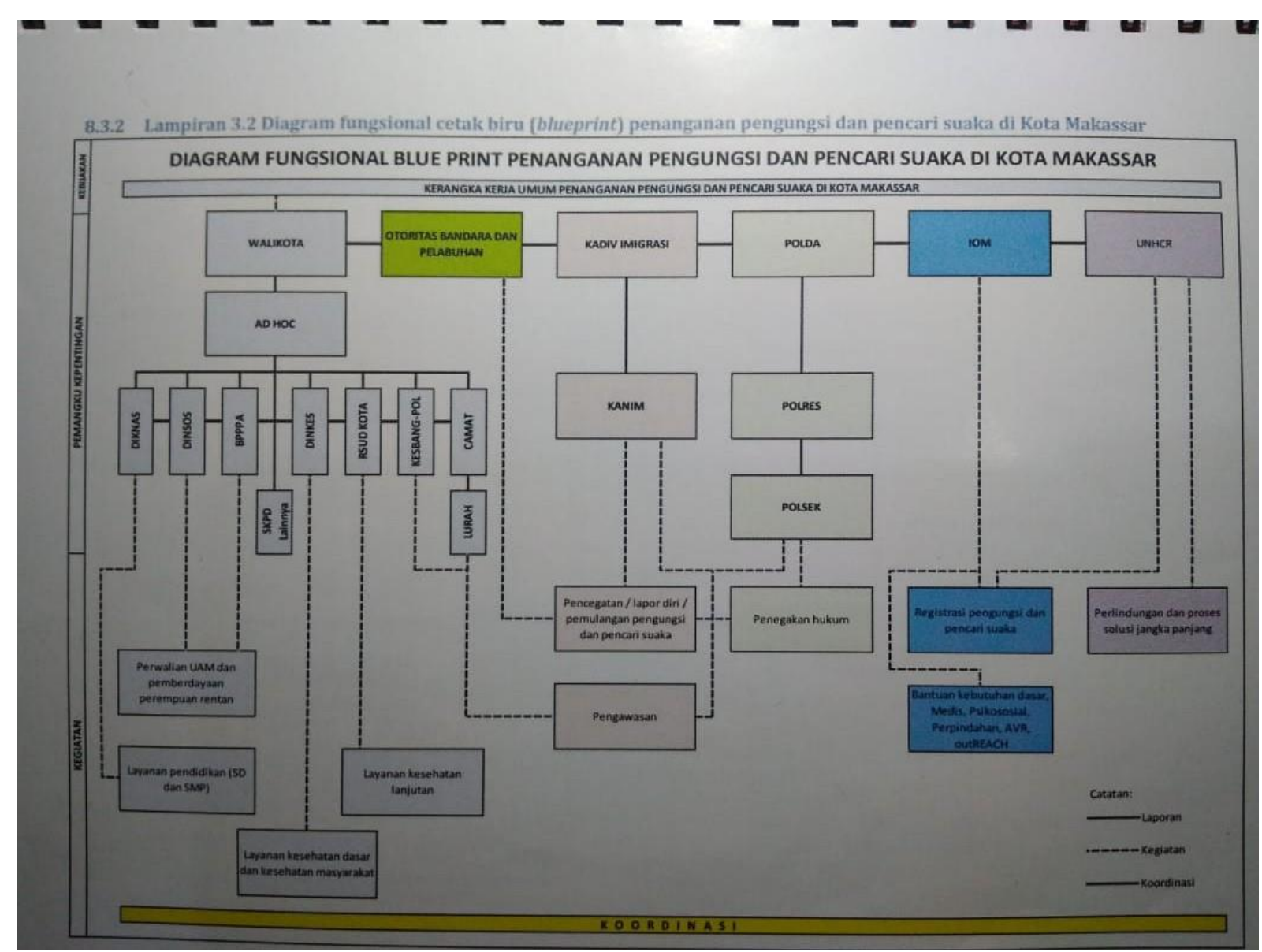

Gambar 1. Jalur Koordinasi Penanganan Pengungsi di Kota Makassar 